Universidade Tecnológica Federal do Paraná - UTFPR Campus Ponta Grossa - Paraná - Brasil

ISSN: 1981-3686/v.9, n.2: p.1910-1919, 2015

D.O.I.: http://dx.doi.org/10.3895/rbta.v9n2.1782
Revista Brasileira de Tecnologia

Agroindustrial

\title{
CONTROLE DE QUALIDADE EM UM LATICÍNIO NA CIDADE DE ITAPECURU-MIRIM, MARANHÃO: CARACTERIZAÇÃO DA QUALIDADE FÍSICO-QUÍMICA E AVALIAÇÃO DE RÓTULOS
}

\section{QUALITY CONTROL IN TOWN A DAIRY ITAPECURU-MIRIN, MARANHÃO: CHARACTERIZATION OF PHYSICAL CHEMISTRY AND QUALITY EVALUATION OF LABELS}

\author{
Nancyleni Pinto Chaves ${ }^{1}$, Alesandra Rocha da Piedade ${ }^{1}$, Kelly Chrisnea Abreu Campos ${ }^{1}$, \\ Nair Pinto Chaves ${ }^{1}$, Danilo Cutrim Bezerra ${ }^{1}$ \\ ${ }^{1}$ Universidade Estadual do Maranhão- São Luís - MA \\ nancylenichaves@hotmail.com
}

\begin{abstract}
Resumo
O objetivo deste estudo foi caracterizar a qualidade físico-química de leite, produtos lácteos e água e avaliar os rótulos dos alimentos produzidos por um laticínio localizado na cidade de ItapecuruMirim, Maranhão. Cinquenta amostras, sendo 18 de leite pasteurizado, 13 de queijos, 10 de bebida láctea, 02 de iogurte e, 07 de água, foram submetidas às análises físico-químicas. Os resultados das análises foram confrontados com as respectivas legislações em vigor. Foram avaliados também os rótulos das amostras de leite e derivados, comparando seus rótulos ao padrão proposto pela ANVISA, averiguando possíveis irregularidades. No período avaliado, apenas duas amostras, sendo uma de leite e outra de queijo, apresentaram parâmetros físico-químicos divergentes das legislações. Dos 43 rótulos avaliados, notou-se 30,23\% de inadequações das informações obrigatórias. A principal irregularidade encontrada foi a ocorrência de vocábulos elou imagens induzindo ao equívoco o consumidor. Desta forma, conclui-se que a qualidade físico-química das amostras estava na sua maioria adequada aos padrões físico-químicos vigentes. Entretanto, as irregularidades observadas nos rótulos podem induzir o consumidor ao uso incorreto destes alimentos.
\end{abstract}

Palavras-chave: produtos lácteos; parâmetros físico-químicos; legislação, rotulagem nutricional.

\section{Introdução}

O agronegócio do leite ocupa destacado espaço na economia mundial. Este sistema agroindustrial é um dos mais expressivos do Brasil pela sua importância social e econômica (GUIMARÃES \& LANGONI, 2009). 
O Brasil ocupa a quinta posição no ranking dos maiores produtores de leite no Mundo, com produção aproximada de 32 bilhões de litros no ano 2011. Na última década, a produção de leite no estado do Maranhão apresentou um crescimento total de aproximadamente 25\%, representando um crescimento anual em torno de 3\% (IBGE, 2011).

No Maranhão, a produção de leite é muito diversificada e se caracteriza por diferentes sistemas de produção. Há produtores muito tecnificados que produzem volumes expressivos de leite e outros que ainda produzem leite em sistemas mais simples, sem muita tecnologia agregada.

O leite e seus derivados são alimentos de elevado valor nutricional, indispensáveis à alimentação do homem, fornecendo macro e micro nutrientes necessários ao crescimento, desenvolvimento e manutenção da saúde, como os carboidratos, proteínas, lipídeos e sais minerais (SILVA et al., 2013).

A qualidade do leite é muito importante para as indústrias e produtores, tendo em vista sua grande influência nos hábitos de consumo e na produção de derivados. Do ponto de vista industrial, a qualidade da matéria-prima está diretamente relacionada às características do produto final, que irá então apresentar melhores características físico-químicas, microbiológicas e sensoriais. Já para o produtor, essa referência vai implicar em uma melhor remuneração e ainda uma maior procura ao seu leite, já que isto reflete a boa sanidade do rebanho. Atingindo o consumidor final, a salubridade do leite gera uma maior segurança do consumo do produto "in natura", assim como de seus derivados lácteos (FREIRE, 2006).

A qualidade nutricional do leite está estreitamente relacionada às características físicoquímicas, sensoriais e microbiológicas. Entretanto, a qualidade físico-química ainda é um sério problema em toda a cadeia produtiva do leite. Muitas pesquisas apontam resíduos de antibióticos (NERO et al., 2007), fraudes por desnate (BELOTI et al., 2011), fraudes por adição de água (FAGAN et al., 2008), e, conservantes (MATTOS et al., 2010), como os principais problemas que afetam a qualidade físico-química deste importante alimento.

Os consumidores no mundo inteiro procuram, cada vez mais, informações sobre os alimentos que consomem. Uma fonte importante para obter esse tipo de informação são os rótulos dos alimentos, que muitas vezes, dispõem de dados sobre o conteúdo nutricional, bem como frases que relacionam o seu consumo com benefícios para a saúde (COUTINHO \& RECINE, 2007).

A segurança alimentar de uma população é definida pela disponibilidade alimentar e pelo acesso aos alimentos em quantidade e qualidade, que levam em consideração os vários elementos que agregam a cadeia agro-alimentar: produtos agrícolas, indústrias, comerciantes, consumidores, além do Estado para uma avaliação do consumo alimentar e seus fatores condicionantes. Neste contexto o estudo foi realizado com o objetivo de caracterizar a qualidade físico-química de leite, 
produtos lácteos e água e avaliar os rótulos dos alimentos produzidos por um laticínio localizado na cidade de Itapecuru-Mirim, Maranhão.

\section{Material e Métodos}

\section{Tipologia e local de estudo}

O estudo possui um desenho descritivo com uma abordagem quantitativa. Quanto ao procedimento técnico adotado é do tipo estudo de caso. O universo dessa pesquisa é um laticínio sob Serviço de Inspeção Estadual (S.I.E) localizado na cidade de Itapecuru-Mirim, estado do Maranhão (MA), com capacidade para processamento de até 10.000 litros de leite/dia.

\section{Coleta das amostras}

Foram realizadas cinco visitas técnicas ao laticínio, no período de março a julho de 2013. Em cada visita técnica foram coletadas 10 amostras, totalizando 50 amostras analisadas, sendo: 18 amostras de leite pasteurizado, 13 amostras de queijo (cinco de queijo mussarela, três de queijo coalho, três de queijo ricota e duas amostras de queijo minas padrão), 10 amostras de bebida láctea (sabores morango e salada de frutas), sete amostras de água utilizada no processamento dos produtos lácteos e, duas amostras de iogurte sabor morango.

A metodologia de coleta foi efetuada de acordo com o Manual de Métodos de Análise Microbiológica de Alimentos (NEUSELY et al., 2007). Todas as amostras à exceção da água foram coletadas em suas embalagens originais, selecionadas de forma aleatória, mas de lotes diferentes. Já, para água foram utilizadas bolsa de coleta plástica com capacidade para $300 \mathrm{~mL}$.

As amostras foram acondicionadas em caixas isotérmicas contendo gelo reutilizável e, imediatamente encaminhadas ao Laboratório de Alimentos da Universidade Estadual do Maranhão.

\section{Análises físico-químicas}

As amostras foram analisadas seguindo as metodologias descritas pelo Instituto Adolf Lutz (2005) e por Lanara (BRASIL, 2005a).

Foram realizadas, para o leite pasteurizado integral, as seguintes análises: matéria gorda, densidade a $15^{\circ} \mathrm{C}$, acidez titulável (expressa em \% de ácido lático), proteínas, índice crioscópico, umidade, cinzas, lactose, extrato seco total (EST), extrato seco desengordurado (ESD). Os resultados foram confrontados com os padrões estabelecidos na Instrução Normativa (IN) $\mathrm{N}^{\circ} 62$ de 29 de dezembro de 2011 do Ministério da Agricultura Pecuária e Abastecimento - MAPA (BRASIL, 2011a). 
Para as amostras de queijo, bebida láctea e iogurte, foram determinados: umidade, teor de gorduras, proteína, $\mathrm{pH}$, cinzas, extrato seco total (EST) e gordura no extrato seco (GES). Os resultados foram confrontados com os padrões estabelecidos no Regulamento Técnico de Identidade e Qualidade de Queijos (BRASIL, 1996), Regulamento Técnico de Identidade e Qualidade de Bebidas Lácteas (BRASIL, 1999), e no Regulamento Técnico de Identidade e Qualidade de Leites Fermentados (BRASIL, 2007).

Foram determinados os seguintes parâmetros físico-químicos para as amostras de água: $\mathrm{pH}$, condutividade elétrica, alcalinidade, oxigênio dissolvido, turbidez, cloretos e teor de manganês, chumbo, ferro, cobre e zinco. Os resultados foram comparados ao padrão de potabilidade fixado pela Portaria $\mathrm{n}^{\circ} 2914$ de 11 de dezembro de 2011 da Agência Nacional de Vigilância Sanitária ANVISA (BRASIL, 2011b).

\section{Análise de rótulos}

Para direcionar a análise dos rótulos das 43 amostras de leite e produtos lácteos, foi elaborada uma ficha de avaliação com base nas Resoluções:

$R D C N^{o} 360$ de 2003: Regulamento Técnico sobre Rotulagem Nutricional de Alimentos Embalados - que torna obrigatória a rotulagem nutricional baseada nas regras estabelecidas com o objetivo principal de atuar em benefício do consumidor e ainda evitar obstáculos técnicos ao comércio (BRASIL, 2003a).

RDC $N^{o} 359$ de 2003: Regulamento Técnico de Porções de Alimentos Embalados para Fins de Rotulagem Nutricional - que estabeleceu que as porções indicadas nos rótulos de alimentos e bebidas embalados foram determinadas com base em uma dieta de $2000 \mathrm{Kcal}$ considerando uma alimentação saudável e foram harmonizadas com os outros países do Mercosul (BRASIL, 2003b).

Paralelamente, analisou-se a tabela de Informação Nutricional dos rótulos dos alimentos para verificar sua adequação em relação à Ingestão Diária Recomendada (IDR) (IOM, 2002). Para tanto, comparou-se os itens de declaração obrigatória: carboidratos em gramas, proteínas em gramas, gorduras totais em gramas, gorduras saturadas em gramas, gorduras trans em gramas, fibra alimentar em gramas e sódio em miligramas com os dados de ingestão recomendada. Também foi verificado o percentual do Valor Diário de Referência (\%VDR) para os itens supracitados, os quais estão baseados em uma dieta de $2000 \mathrm{kcal}$, a fim de investigar sua adequação com a dieta para uma pessoa adulta. Considerou-se nesse trabalho que os dados nutricionais apresentados nos rótulos dos produtos analisados foram mensurados corretamente através de métodos validados. 


\section{Análise de dados}

As informações das análises físico-químicas foram armazenadas em um banco de dados utilizando o programa Microsoft Access ${ }^{\circledR}$. Utilizou-se a análise estatística descritiva por meio de distribuições absoluta e relativa para expressar os resultados obtidos nesta pesquisa.

\section{Resultados e Discussão}

Das 50 amostras analisadas, duas $(\mathrm{n}=02 / 50 ; 4 \%)$ estavam em desacordo com os padrões físico-químicos exigidos pela legislação, sendo uma amostra de queijo coalho (BRASIL, 1996) e outra de leite pasteurizado integral (BRASIL, 2011a), como mostra a Tabela 1. A totalidade das amostras de bebida láctea, iogurte e de água estavam em conformidade com os padrões físicoquímicos vigentes (BRASIL, 1999; BRASIL, 2007; BRASIL, 2011b) (Tabela 1).

Tabela 1 - Conformidade dos produtos de um laticínio sob Serviço de Inspeção Estadual (SIE) na cidade de ItapecuruMirim e porcentagem das amostras não conformes de acordo com o ensaio físico-químico, 2013.

\begin{tabular}{|c|c|c|c|c|c|c|}
\hline \multirow{2}{*}{ Produto } & \multirow{2}{*}{ Amostras (n) } & \multicolumn{2}{|c|}{ Conforme } & \multicolumn{2}{|c|}{ Não conforme } & \multirow{2}{*}{$\begin{array}{c}\text { Porcentagem das amostras } \\
\text { não conformes de } \\
\text { acordo com o ensaio* }\end{array}$} \\
\hline & & $\mathbf{N}$ & $\%$ & $\mathbf{N}$ & $\%$ & \\
\hline $\begin{array}{l}\text { Leite pasteurizado } \\
\text { integral }\end{array}$ & 18 & 17 & 94,45 & 01 & 5,55 & $5,55 \%$ de $\mathrm{MG}$ \\
\hline \multicolumn{7}{|l|}{ Queijos } \\
\hline Mussarela & 05 & 05 & 100 & 00 & 00 & 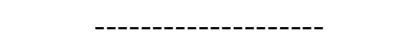 \\
\hline Coalho & 03 & 02 & 66,67 & 01 & 33,33 & $7,69 \% \mathrm{Um}$ \\
\hline Ricota & 03 & 03 & 100 & 00 & 00 & --------------------- \\
\hline Minas & 02 & 01 & 100 & 00 & 00 & --------------------- \\
\hline \multicolumn{7}{|l|}{ Bebida láctea } \\
\hline Sabor morango & 06 & 06 & 100 & 00 & 00 & --------------------- \\
\hline $\begin{array}{l}\text { Sabor salada de } \\
\text { fruta }\end{array}$ & 04 & 04 & 100 & 00 & 00 & ----------------- \\
\hline Iogurte & 02 & 02 & 100 & 00 & 00 & -------------------- \\
\hline Água & 07 & 07 & 100 & 00 & 00 & ---------------------- \\
\hline Total & 50 & 48 & 96 & 02 & 04 & |----------------------- \\
\hline
\end{tabular}

A amostra de leite pasteurizado integral estava em desconformidade com a legislação, no parâmetro teor de matéria gorda, apresentando valor inferior ao recomendado (2,2\%). A avaliação do percentual de gordura é essencial, uma vez que há um limite mínimo previsto pela legislação que é de 3\% (BRASIL, 2011a).

A gordura é utilizada para a produção de alguns derivados como manteiga e creme de leite (PERRY, 2004). Portanto, a sua determinação é necessária para a verificação de fraudes por desnate. Nesta situação em particular, não foi evidenciada elevação da densidade da amostra em 
questão e nem índice crioscópico compatível com adição de água, pois ambos os parâmetros estavam dentro do previsto pela IN Nº 62 de 2011 (BRASIL, 2011a).

De acordo com o Regulamento Técnico de Identidade e Qualidade de Queijos (BRASIL, 1996), estes alimentos são classificados quanto ao teor de umidade em: queijos de média umidade (36\% < umidade < 46\%) e queijos alta umidade $(46 \%<$ umidade < 55\%). A amostra de queijo coalho $(n=1 / 3 ; 3,33 \%)$ em desconformidade com a legislação, apresentou teor de umidade inferior a $46 \%$, ou seja, valor inferior ao fixado pela Portaria № 146 , de 07 de1996.

O queijo coalho é considerado de alta umidade, cozido ou semi-cozido, com gordura no extrato seco na faixa de 35 a 60\%, textura compacta e macia (BRASIL, 2001). O teor de umidade dos queijos influencia sobremaneira na textura e no sabor do produto, sendo facilmente controlado quando se trata de fabricação industrial, como no laticínio em questão, apesar da desconformidade identificada.

Os rótulos dos alimentos foram analisados para verificar a adequação quanto à presença de vocábulos e/ou imagens que induzem a erros o consumidor; denominação de venda; lista de ingredientes; identificação de origem, lote e data de validade; instruções sobre o armazenamento e preparo do alimento; tabela de informação nutricional completa com porção alimentar em gramas ou mililitros e medida caseira correspondente.

Dos 43 rótulos avaliados, identificou-se 30,23\% ( $n=13)$ de irregularidades das informações obrigatórias estabelecidas pelas RDC No 360 e RDC N 359 da ANVISA (BRASIL, 2003a; BRASIL, 2003b). Todas as amostras em desconformidades eram amostras de leite pasteurizado integral, o que representa $72,22 \%(\mathrm{n}=13)$ das amostras de leite analisadas.

Os dados apresentados na Tabela 2 causam preocupação, pois, a rotulagem de alimentos é o principal elo entre o consumidor e o produto. Destaca-se a ocorrência de vocábulos e/ou imagens que levam ao equívoco do consumidor em $100 \%(\mathrm{n}=13)$ das embalagens de leite pasteurizado em desconformidade com as resoluções, no período avaliado. Vale ressaltar que o leite produzido por este laticínio é comercializado em todo o estado do Maranhão, consumido por adultos, crianças e senis e, até pouco tempo integrava o programa do leite do governo do estado, que o distribuía em escolas para merenda escolar e para famílias de baixa renda.

A aquisição de produtos influenciada por estratégias de mercado, acrescida pelas irregularidades apontadas nos rótulos podem causar danos à saúde do consumidor e prejuízos econômicos. As constantes modificações na legislação sobre rotulagem de alimentos, aliada à fiscalização insuficiente podem ter contribuído para os resultados encontrados nesta pesquisa.

Os rótulos são elementos essenciais de comunicação entre produtos e consumidores. Assim, é necessário que as informações sejam claras e possam auxiliar na escolha adequada dos alimentos. Dados levantados junto à população demonstram que aproximadamente $70 \%$ das pessoas consultam 
os rótulos dos alimentos no momento da compra, no entanto, mais da metade não compreende adequadamente seu significado (BRASIL, 2007).

Tabela 2 - Irregularidades na rotulagem de 13 amostras leite pasteurizado integral produzido em um laticínio do município de Itapecuru - Mirim, Maranhão, 2013.

Amostras

Irregularidade

\begin{tabular}{llc}
\multicolumn{1}{c}{ Irregularidade } & $\mathbf{N}$ & $\%$ \\
\hline Uso de vocábulos e imagens que induzem a erro & 13 & 100 \\
\hline $\begin{array}{l}\text { Ausência de orientação quanto à correta conservação de } \\
\text { alimentos perecíveis }\end{array}$ & 03 & 23,07 \\
\hline $\begin{array}{l}\text { Não possui identificação do lote visível, legível e } \\
\text { indelével }\end{array}$ & 03 & 23,07 \\
\hline $\begin{array}{l}\text { Ausência de porção alimentar em g ou mL e medida } \\
\text { caseira correspondente }\end{array}$ & 02 & 15,38 \\
\hline $\begin{array}{l}\text { Ausência de identificação da origem completa } \\
\text { discriminada no rótulo }\end{array}$ & 02 & 15,38 \\
\hline $\begin{array}{l}\text { Não apresenta prazo de validade de forma clara e precisa } \\
\text { Incorreta denominação de venda do produto }\end{array}$ & 02 & 15,38 \\
\hline
\end{tabular}

A importância da rotulagem nutricional dos alimentos para a promoção da alimentação saudável é destacada em grande parte dos estudos e pesquisas que envolvem a área da nutrição e sua relação com estratégias para a redução do risco de doenças crônicas como: diabetes melitus, hipertensão, doença celíaca e intolerância à lactose (BRASIL, 2007).

A rotulagem nutricional é toda inscrição destinada a informar ao consumidor sobre as propriedades nutricionais dos alimentos (BRASIL, 2005b). A legislação brasileira vigente acerca da rotulagem de produtos alimentícios é satisfatória e pode ser comparada às de países de primeiro mundo em quase todos os aspectos, segundo Celeste (2001), porém o cumprimento dessa legislação por parte das indústrias é de crucial importância, já que os rótulos alimentares são elementos essenciais de comunicação entre produtos e consumidores. Para Matta et al. (2006) sua implementação e a fiscalização são incipientes, fazendo com que as informações nos rótulos não sejam declaradas de forma precisa.

Com relação à avaliação da Tabela de Informação Nutricional dos rótulos das amostras deste estudo observou-se que $100 \%(n=43)$ apresentaram dados calculados para uma dieta de $2000 \mathrm{kcal}$. Foram seguidas também as regras de arredondamento, os subscritos obrigatórios, bem como a identificação de gordura trans ("VD não estabelecido"). Desta forma não foram encontradas divergências em relação aos padrões estabelecidos pela ANVISA (BRASIL, 2005b). 
Para Ferreira e Lanfer-Marques (2007), o Brasil aperfeiçoou sua legislação referente à rotulagem nutricional de alimentos ao longo das últimas quatro décadas. Contudo, estes pesquisadores consideram uma involução a exclusão da obrigatoriedade das declarações do conteúdo de ferro, cálcio e colesterol, embora se justifique com relação à harmonização da legislação com países do Mercosul, permitindo o livre comércio entre eles. Os autores afirmam ainda que a rotulagem nutricional de alimentos é um apoio valioso para os consumidores, dandolhes a oportunidade de conhecer a composição do alimento, a segurança com relação à ingestão e manutenção da saúde.

\title{
4 Conclusão
}

A partir dos resultados obtidos pode-se concluir que:

- A qualidade físico-química das amostras analisadas estava na sua maioria adequada aos padrões físico-químicos vigentes;

- A análise de rótulos dos produtos identificou muitas irregularidades em relação à legislação, com destaque para a utilização de vocábulos e imagens que induzem a erro;

- As inadequações observadas podem induzir o consumidor ao uso incorreto destes produtos;

- É necessária maior fiscalização dos órgãos responsáveis, de modo a assegurar que os rótulos alimentares forneçam informações de acordo com as normas adotadas para cada tipo de alimento;

- Embora a legislação brasileira sirva de exemplo para outros países, na prática, ainda há aspectos a serem melhorados, já que muitas empresas ainda não se adequaram às legislações.

\begin{abstract}
The aim of this study was to characterize the physico-chemical quality of milk, dairy products and water and evaluate food labels produced by a dairy located in the municipality of Itapecuru Mirim, Maranhão. Fifty samples and 18 pasteurized milk, 13 cheeses, 10 kefir, yogurt and 02,07 of water, were subjected to physic-chemical analysis. The analysis results were compared with their respective laws in force. Were also evaluated samples of milk and dairy products, comparing their labels to the proposed standard by ANVISA, checking possible irregularities. In the study period, only two samples, one for milk and other cheese, presented divergent physicochemical parameters of the laws. Among the 43 labels evaluated, it was noted inadequacies $30.23 \%$ of the mandatory information. The main error was found to occur words and / or images leading mistake to the consumer. Thus, it is concluded that the physico-chemical quality of the samples was mostly suitable for the physical-chemical standards in force. However, the irregularities observed in the labels may cause consumers to misuse these foods.
\end{abstract}

Key-words: dairy products; physico-chemical parameters; legislation, nutrition labeling. 


\section{REFERÊNCIAS}

BELOTI, V.; RIBEIRO JÚNIOR, J. C.; TAMANINI, R.; YAMADA, A. K.; CAVALETTI, L.; SHECAIRA, C. de L.; NOVAES, D. G.; SILVA, F. F. da. Qualidade microbiológica e físico-química do leite cru refrigerado produzido no município de Sapopema/PR. Revista Científica Eletrônica de Medicina Veterinária, v.9, n.16, 2011.

BRASIL. Ministério da Agricultura do Abastecimento e da Reforma Agrária. Portaria n ${ }^{\circ} 146$, de 07 de março de 1996. Aprova os Regulamentos Técnicos de Identidade e Qualidade dos Produtos Lácteos. Diário Oficial [da] República Federativa do Brasil, Brasília, DF, 11 de março de 1996, Seção I. p. 3977.

BRASIL. Ministério da Agricultura. Regulamento da Agricultura e do Abastecimento. Regulamento técnico de identidade e qualidade de bebidas lácteas. DAS/SIPOA. Diário Oficial [da] República Federativa do Brasil, Brasília, DF, 08 de dezembro de 1999. Seção I. n. 234, p. 46-49.

BRASIL. Ministério da Agricultura, Pecuária e Abastecimento. Regulamentos técnicos de identidade e qualidade de manteiga da terra ou manteiga de garrafa, queijo de coalho e queijo de manteiga. Instrução Normativa $n^{\circ} 30$, de 26/06/2001. Diário Oficial [da] República Federativa do Brasil, Brasília, DF, 16 julho de 2001. Seção I, p. 13-15.

BRASIL. Resolução RDC $\mathbf{n}^{\circ}$ 360, de 23 de Dezembro de 2003a. Aprova regulamento técnico sobre rotulagem nutricional de alimentos embalados, tornando obrigatória a rotulagem nutricional. Diário Oficial [da] República Federativa do Brasil, Brasília, DF, 26 de dez 2003a; Seção I, p. 33.

BRASIL. Resolução RDC $\mathbf{n}^{\circ}$ 359, de 23 de Dezembro de 2003b. Aprova regulamento técnico de porções de alimentos embalados para fins de rotulagem nutricional. Diário Oficial [da] República Federativa do Brasil, Brasília, DF, 26 de dez 2003b; Seção I, p. 28.

BRASIL. Ministério da Saúde. Agência Nacional de Vigilância Sanitária. Métodos físico-químicos para análise de alimentos. Brasília: Ministério da Saúde, 2005a. 1017p.

BRASIL. Ministério da Saúde. Agência Nacional de Vigilância Sanitária- Alimentos-Rotulagem nutricional obrigatória - Manual de Orientação ao Consumidor. $2^{a}$ versão. Brasília: Universidade de Brasília, 2005b. 44p.

BRASIL. Ministério da Agricultura Pecuária e Abastecimento. MAPA. Instrução Normativa n 46, de 23 de outubro de 2007, que adota o Regulamento Técnico de Identidade e Qualidade de Leites Fermentados. Diário Oficial [da] República Federativa do Brasil, Brasília, Distrito Federal, em 24 de outubro de 2007. Seção I, p. 5.

BRASIL. Ministério da Agricultura, Pecuária e Abastecimento. Instrução Normativa no 62, de 29 de dezembro de 2011a. Aprova o Regulamento Técnico de Produção, Identidade e Qualidade do Leite tipo A, o Regulamento Técnico de Identidade e Qualidade de Leite Cru Refrigerado, o Regulamento Técnico de Identidade e Qualidade de Leite Pasteurizado e o Regulamento Técnico da Coleta de Leite Cru Refrigerado e seu Transporte a Granel, em conformidade com os Anexos desta Instrução Normativa. Diário Oficial [da] República Federativa do Brasil, Brasília, DF, 30 dezembro de 2011. Seção I, p. 6.

BRASIL. Ministério da Saúde. Portaria n. 2914, de 12 de dezembro de 2011b. Dispõe sobre os procedimentos de controle e de vigilância da qualidade da água para consumo humano e seu padrão de potabilidade. Diário Oficial [da] República Federativa do Brasil, Brasília, DF, 14 de dezembro de 2011. p. 19.

CELESTE, R. K. Análise comparativa da legislação sobre rótulo alimentício do Brasil, Mercosul, Reino Unido e União Européia. Revista de Saúde Pública, v.35, n.3, p.217- 223, 2001. http://dx.doi.org/10.1590/S003489102001000300001

COUTINHO, J. G.; RECINE, E. Experiências internacionais de regulamentação das alegações de saúde em rótulos de alimentos. Revista Panamericana Salud Publica, v.22, n.6, p.432-437, 2007. http://dx.doi.org/10.1590/S102049892007001100012

FAGAN, E. D.; TAMANINI, R.; FAGNANI, R.; BELOTI, V.; BARROS, M. de A. F.; JOBIM, C. C. Avaliação de padrões físicoquímicos e microbiológicos do leite em diferentes fases de lactação nas estações do ano em granjas leiteiras no Estado do Paraná - Brasil. Semina: Ciências Agrárias, v.29, n.3, p.651-650, 2008. http://dx.doi.org/10.5433/1679-0359.2008v29n3p651 
FERREIRA, A. B.; LANFER-MARQUES, U. M. Legislação brasileira referente à rotulagem nutricional de alimentos. Revista de Nutrição, v.20, n. 1, p.83-93, 2007. http://dx.doi.org/10.1590/S1415-52732007000100009

FREIRE, M. F. Análise das características físico-químicas de leite cru refrigerado entregue em uma cooperativa no estado do Rio de Janeiro no ano de 2002. Rio de Janeiro, 2006. 33 f. Monografia (Especialização Higiene e Inspeção de Produtos de Origem Animal e Vigilância Sanitária) - Universidade Castelo Branco.

GUIMARÃES, F. F.; LANGONI, H. Leite: alimento imprescindível, mas com riscos para a saúde pública. Revista Veterinária e Zootecnia, v.16, n.1, p.38-51, 2009.

IAL. Instituto Adolfo Lutz. Normas Analíticas do Instituto Adolfo Lutz. 4a ed. São Paulo: IAL, 2005.

IBGE. Instituto Brasileiro de Geografia e Estatística. Produção da Pecuária Municipal - 2011. 2011. Disponível em: http://www.ibge.gov.br/home/estatistica/economia/ppm/2011/default.shtm. Acesso em: 22 de out. 2013.

IOM. Institute of Medicine. Dietary intake 2001/2002. Disponível em: www.iom.edu/Object.File/Master/21/372/0.pdf. Acesso em: 15 de ago. 2013.

MATTA, I. E. A.; HENRIQUES, P.; SILVA, Y. Adequação à legislação vigente da rotulagem de alimentos diet e light comercializados no Rio de Janeiro, RJ. Revista Higiene Alimentar, v.20, n.147, p.97-103, 2006.

MATTOS, M. R.; BELOTI, V.; TAMANINI, R.; MAGNANI, D. F.; NERO, L. A.; BARROS, M. de A. F.; PIRES, E. M. F.; PAQUEREAU, B. P. D. Qualidade do leite cru produzido no Agreste de Pernambuco. Semina: Ciências Agrárias, v.31, n.1, p.173-182, 2010. http://dx.doi.org/10.5433/1679-0359.2010v31n1p173

NERO, L. A.; MATTOS, M. R.; BELOTI, V.; BARROS, M. A. F.; FRANCO, B. D. G. M. Resíduos de antibióticos em leite cru de quatro regiões leiteiras no Brasil. Ciência e Tecnologia de Alimentos, v.27, n.2, p.391-393, 2007. http://dx.doi.org/10.1590/S0101-20612007000200031

NEUSELY, S.; JUNQUEIRA, V. C. A.; SILVEIRA, N. F. A. Manual de Métodos Microbiológicos de Alimentos. $3^{\mathrm{a}}$ ed. São Paulo: Ed. Varela. 2007. 536 p.

PERRY, K. S. P. Queijos: aspectos químicos, bioquímicos e microbiológicos. Química Nova, v. 27, n. 2, p. 293-300, 2004. http://dx.doi.org/10.1590/S0100-40422004000200020

SILVA, J. B. A.; CARVALHO, S. D. M.; ABRANTES, M. R.; MENDES, C. G.; REBOUÇAS, G. G.; BANDEIRA, M. G. L.; ALVES, J. S. C. Qualidade de queijos comercializados na cidade de Recife-PE. Revista Veterinária e Zootecnia, v. 20, n. 2, Suplemento 1, p. 249-250, 2013.

Submetido em 04 jan. 2014, Aceito para publicação em 11 jan. 2015, Publicado em 10 dez. 2015. 